\title{
404 中間変数を用いた流速圧力分離解法のシェル構造-流体一体型解析への適用 \\ Application of decoupled method using intermediate variable to monolithic analysis of shell-fluid interaction
}

○正 石原 大輔(九工大院) 岡村 尚樹(九工大院) 正 堀江 知義(九工大院) 正 二保 知也 (九工大院)

Daisuke ISHIHARA, Kyushu Institute of Technology

Naoki OKAMURA, Tomoyoshi HORIE and Tomoya NIHO

Key words: Fluid-Structure Interaction, Decoupled Method, Monolithic Method, Shell Structure, Incompressible Viscous Fluid

\section{1. 緒言}

流体構造連成解析手法は分離型解法と一体型解法に大別され，そ れぞれ一長一短ある. 分離型解法は既存の優れた解析コードを有効 利用でき,また強連成問題への適用 (1)(2) が近年急速に進んでいる. 一方, 一体型解法は強連成問題一の適用例が多い. ゆえにその久点 の改善を進め, 利用者が 2 つの解法の長所短所を理解した上で, 連 成問題に応じてそれらを使い分けられる体制が望ましい. 一体型解 法の欠点のひとつとして, 連成方程式の係数行列が悪条件と成り易 いことが挙げられる. ゆえにその改善手法 ${ }^{(3)(4)}$ が提案されている. 本研究では, 中間变数を用いた流速圧力分離解法に基づく一体型解 法 ${ }^{(5)}$ (6) がシェル構造 - 流体一体型解析における上述の欠点に対し て有効かどうかを検討するため, その適用と精度検証を行う.

\section{2. 流速圧力分離型解法の適用とその増分型定式化}

本研究では, 構造大変形を扱うために, 中間変数を用いた流速圧 力分離型解法の一体型解法への適用 ${ }^{(5),(6)}$ を増分型で定式化する.

非圧縮性粘性流体と弾性体の連成現象における有限要素離散化 された運動方程式を次式のように記述する.

$\mathbf{q}_{i}^{\mathrm{s}}=\mathbf{g}_{i}^{\mathrm{s}}, \mathbf{q}_{c}^{\mathrm{s}}+\mathbf{q}_{c}^{\mathrm{f}}=\mathbf{g}_{c}^{\mathrm{sf}}, \mathbf{q}_{i}^{\mathrm{f}}=\mathbf{g}_{i}^{\mathrm{f}}$ $(1 \mathrm{a}, \mathrm{b}, \mathrm{c})$

ここでq は連動方程式の左辺の全ての項を含む等価内力ベクトル, $\mathrm{g}$ は外力ベクトル, ベクトルの右上付添え字 $\mathrm{s}, \mathrm{f}$ はそれぞれ構造, 流体の諸量, ベクトルの右下付添え字 $i, c$ はそれぞれ構造流体の 非連成，連成の自由度であることを表す．時刻 $t+\Delta t$ における反復 計算 $k$ を用いて, 式 (1) を満たす未知の加速度 ${ }^{1+\Delta} \mathbf{a}$, , 速度 ${ }^{1+\Delta}{ }_{k} \mathbf{v}$, 変位 ${ }^{++\Delta}{ }_{k} \mathrm{U}$ を求める. 反復 $k-1$ から $k$ までの加速度, 速度, 変位, 圧力の増分 $\Delta \mathbf{a}, \Delta \mathbf{v}, \Delta \mathbf{u}, \Delta \mathbf{p}$ を用いて, 式（1）を線形化すると,

$$
{ }_{k-1}^{i+\Delta} \mathbf{M}^{*} \Delta \mathbf{a}-\mathbf{G} \Delta \mathbf{p}=\Delta \mathbf{g}
$$

を得る. 式 (2) の倸数行列 $\mathbf{M}_{*}, \mathbf{G}$ と残差べクトル $\Delta \mathbf{g}$ は $\mathbf{M}^{*}=\left[\begin{array}{ccc}\mathrm{L}_{\mathrm{L}} \mathbf{M}_{i i}^{\mathrm{s}} & \mathbf{0} & \mathbf{0} \\ \mathbf{0} & { }_{\mathrm{L}} \mathbf{M}_{i i}^{\mathrm{s}}{ }_{\mathrm{L}} \mathbf{M}_{i i}^{\mathrm{f}} & \mathbf{0} \\ \mathbf{0} & \mathbf{0} & { }_{\mathrm{L}} \mathbf{M}_{i i}^{\mathrm{f}}\end{array}\right]+\left[\begin{array}{ccc}\beta \Delta t^{2} \mathbf{K}_{i i}^{\mathrm{s}} & \beta \Delta t^{2} \mathbf{K}_{i c}^{\mathrm{s}} & \mathbf{0} \\ \beta \Delta t^{2} \mathbf{K}_{c i}^{\mathrm{s}} & \beta \Delta t^{2} \mathbf{K}_{c c}^{\mathrm{s}} & \mathbf{0} \\ \mathbf{0} & \mathbf{0} & \mathbf{0}\end{array}\right]$ ${ }_{\mathbf{\tau}} \mathbf{G}=\left[\begin{array}{lll}\mathbf{0} & \mathbf{G}_{c} & \mathbf{G}_{i}\end{array}\right], \Delta \mathbf{g}==_{\mathrm{\tau}}\left[\Delta \mathbf{g}_{i}^{\mathrm{s}}, \Delta \mathbf{g}_{c}^{\mathrm{sf}}, \Delta \mathbf{g}_{i}^{\mathrm{f}}\right]==_{\mathrm{\tau}}\left[\mathbf{g}_{i}^{\mathrm{s}}-\mathbf{q}_{i}^{\mathrm{s}}, \mathbf{g}_{c}^{\mathrm{sf}}-\mathbf{q}_{c}^{\mathrm{sf}}, \mathbf{g}_{i}^{\mathrm{f}}-\mathbf{q}_{c}^{\mathrm{f}}\right]$ である.ここで $\mathbf{M}, \mathbf{K}, \mathbf{G}$ はそれぞれ質量, 接線用性, 圧力勾配の

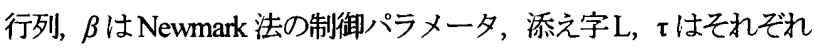

行列の対角集中化，転置を表す. 式 (2) の導出において, 質量行 列の対角集中化, 流体の移流 - 拡散項の既知の流体速度 ${ }^{+\Delta-1}{ }_{k-1} v^{f}$ によ る評価, Newmark 法に基づく変位 ・速度 ・加速度増分間の関倸式 $\Delta \mathbf{v}=\gamma \Delta \Delta \Delta \mathrm{a}, \Delta \mathrm{u}=\beta \Delta \Delta^{2} \Delta \mathrm{a}$ を適用している. 次に既知の圧力 ${ }^{++\Delta}{ }_{k-1} \mathrm{p}$ に対

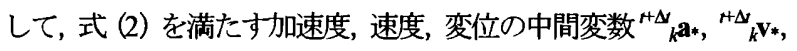

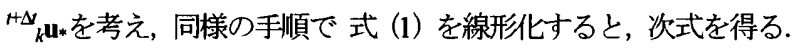

${ }_{k \rightarrow 1}^{t+\Delta t} \mathbf{M}^{*} \Delta \mathbf{a}_{*}=\Delta \mathbf{g}$

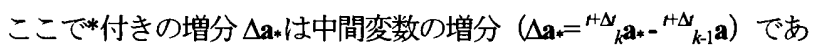
ることを示す. 式 (2)，（3）の辺々を引くことで次式を得る.

${ }_{k-1}^{t+\Delta t} \mathbf{M}^{*}\left({ }^{1+\Delta t} \mathbf{v}-{ }^{1+{ }_{k} t} \mathbf{v} \cdot\right)-\gamma \Delta t \mathbf{G} \Delta \mathbf{p}=\mathbf{0}$

但し, $\Delta \mathrm{a}-\Delta \mathbf{a}_{*}=\left({ }^{++\Delta}{ }_{k} \mathbf{v}^{(k)}-{ }^{H+\Delta}{ }_{k} \mathbf{v}^{*}\right) / \gamma \Delta t$ の関係を用いた. 式 (4) の雨辺 に左から $\mathrm{G}_{\mathrm{L}} \mathrm{M}^{-1}$ を掛け, 速度とその中間変数の差が反復計算過程 で0に漸近することを利用すると，最終的に次式を得る.

$\gamma \Delta t_{\tau} \mathbf{G}_{1} \mathbf{M}^{-1} \mathbf{G} \Delta \mathbf{p}={ }_{\tau} \mathbf{G}^{i+\Delta t}{ }_{k} \mathbf{v}-{ }_{\tau} \mathbf{G}^{\prime+\Delta t}{ }_{k} \mathbf{v}$

上式の右辺第 1 項 $=\mathbf{0}$ は非圧縮性条件と等価なので, 非圧縮性条件 を解く代わりに, 次式の圧力ポアソン方程式を解くことができる.

$\gamma \Delta t_{\mathbf{r}} \mathbf{G}_{\mathbf{L}} \mathbf{M}^{-1} \mathbf{G} \Delta \mathbf{p}=-_{\mathbf{r}} \mathbf{G}^{\prime+\nu}{ }_{k} \mathbf{v}$.

以上をまとめると，本解法による解析の流孔は次のようになる. Step1 : 式 (3) を解いて, $\Delta \mathbf{a}$ *を得て, それから ${ }^{++\Delta}{ }_{k} \mathbf{v} *$ を得る,

Step2：式（6）を解いて， $\Delta \mathbf{p}$ を得る,

Step3 : 最後に, 式 (2) を解いて, $\Delta$ をを得る.

通常の一体型解法では, 連成方程式(運動方程式十非圧縮性条件) を解くのに対し, 本解法では連成方程式を分離して, 運動方程式と 非圧縮性条件に対応する圧力ポアソン方程式を解く.ゆえに通常の 一体型解法に比べ, 本解法の方が反復法ソルバーを利用し易く, 大 規模解析に適している. 本研究ではCG 法を用い, 流体領域のみ領 域分割に基づく並列化を行った.

構造がシェルの場合, その厚さは面内の大きさに比べ, かなり小 さいので, 周囲の流体メッシュをシェル構造の幾何形状に合わせる と, 必要以上の節点数・要素数となる可能性がある. そこでシェル 
構造の中立面上の同じ位置に流体節点を 2 重に配置し，1 つは表, もう 1 つは裏の面に対応させる. シェル構造の中立面上で構造節点 と流体節点の位置が一致すると仮定して, 次の補間関係式を構造と 流体の間の連続・平衡条件に，構造節点毎に導入する.

${ }_{\tau} \mathbf{T}_{c} \mathbf{v}_{c}^{\mathrm{s}}={ }_{\tau}\left[\mathbf{v}_{c 0}^{\mathrm{f}}, \mathbf{v}_{c 1}^{\mathrm{f}}\right], \mathbf{q}_{c}^{\mathrm{s}}+\mathbf{T}_{c \tau}\left[\mathbf{q}_{c 0}^{\mathrm{f}}, \mathbf{q}_{c 1}^{\mathrm{f}}\right]=\mathbf{g}_{c}^{\mathrm{sf}}, \mathbf{T}_{c}=\left[\begin{array}{ll}1 & 1\end{array}\right] \cdots \quad(7)$

ここで補間行列 $\mathbf{T}$ と速度·等価内力ベクトルの積の演算において, 形式的にベクトルをスカラーのように扱っている. また右下添え字 $c$ は構造節点を表し，それに対する流体節点を $00, c 1$ としている.

\section{3. 流体中で大移動・大変形する翼の解析と実験との比較 3.1 問題設定}

本解法を用いて, 流体中で羽ばたく翼の解析を行う. 図 1 に問題 設定の概要を示す. 翼 (翼長 $L_{\mathrm{w}}=0.225 \mathrm{~m}$, 翼弦長 $c=0.043 \mathrm{~m}$, 質 量密度 $\rho^{\mathrm{s}}=1.0 \times 10^{3} \mathrm{~kg} / \mathrm{m}^{3}$ )がシリコン油(質量密度 $\rho^{\mathrm{f}}=9.6 \times 10^{2} \mathrm{~kg} / \mathrm{m}^{3}$, 粘性係数 $\mu=0.048 \mathrm{~kg} /(\mathrm{cm} \mathrm{s})$ ) 中で, 大きくストローク運動する（ス トローク角 $\Phi=123 \mathrm{deg}$, ストローク周波数 $f_{\varphi}=0.521 \mathrm{~Hz}$ ). 図 1 の 翼の柔軟部分 (図 1 の翼の白い部分, 翼弦方向長さ $c_{\mathrm{fp}}=1.0 \times 10^{-2} \mathrm{~m}$, 板厚 $t_{\mathrm{fq}}=3.0 \times 10^{-4} \mathrm{~m}$, ヤング率 $\left.E_{\mathrm{fp}}=6.56 \times 10^{9} \mathrm{~Pa}\right)$ が大変形し, 高い 迎角（たわみ角の最大は約 $50 \mathrm{deg}$ ） が発生する. 翼の柔軟部分以 外は用体板として振舞うように，ヤング率と板厚を設定している. 詳細は文献 (9) に譲るが, 以上の問題設定は, 八エ目の昆虫 (Tipula obsoleta, ガガンボの 1 種) の羽ばたき飛行（無次元数 : ストロー ハル数 $S t=0.0726$, レイノルズ数 $R e=254 ）$ を, 流体構造連成現象 の力学的相似則を用いて, 翼長約 $1 \mathrm{~cm}$ から約 $23 \mathrm{~cm}$ にスケール拡大 し, 実験的にその力学量を測定できるようにしたものである. 但し， 本研究では, メッシュ作成を容易にするため, 翼を長方形としてい る. 翼のメッシュは MITC シェル要素の を用いて節点数 121 ・要 素数 100 , 流体領域のメッシュは P1P1 要素 ${ }^{(8)}$ を用いて節点数 46,911 - 要素数 254,352 とした. 流体解析の安定化のために SUPG/PSPG 法を用いる. 時間刻みはストローク周期 $T_{\varphi}$ の 1/5000 とした. ストローク角速度の時刻歴を図 2 のように与える. 同図の 加減速時間 $t_{\mathrm{a}}$ を $T_{\phi} / 10, T_{\phi} / 8, T_{\phi} / 6, T_{\phi} / 4$ とする.

\section{2 解析結果と考察}

$t_{\mathrm{a}}=T_{\phi} / 8$ とした場合の時刻 $6.25 \mathrm{cycle}$ における翼の変形とある翼弦 が運動する円筒面上の流速べクトル場を図 3 に示寸. また解析と実 験により得られた翼への揚力の時刻歴を図 4 に示寸. 図 3 に示寸よ うに, 昆虫羽ばたき飛行に特幑的な前縁渦の形成が捉えられている. また図 4 に示すように， $t_{\mathrm{a}}$ の増加に伴う揚力時刻歷の特徵の変化を 本解析結果が良く捉えており，定量的にも実験結果と良く一致して いることが判る.

\section{4. 結言}

本研究では, 中間変数を用いた流速圧力分離型解法をシェル構造 - 流体連成の一体型解析に適用した. 適用においては, 構造大変形 を取り扱うために増分型で定式化した. 本解法を流体中で大きくス トローク運動し，大変形する羽ばたき翼の解析に適用したところ， 実験結果と良く一致する結果を得た. 今後は大規模強連成解析への 有効性を検討する。
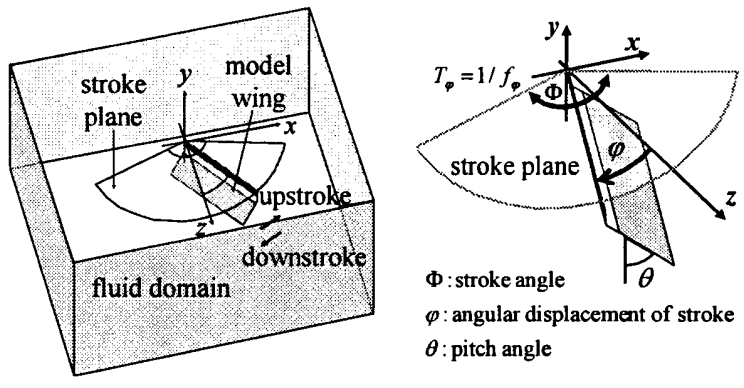

Fig. 1 Schematic view of our model wing flight

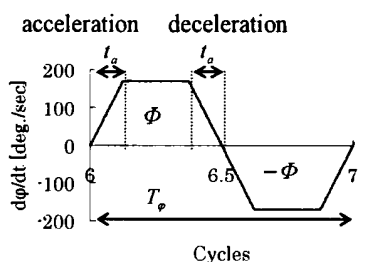

Fig. 2 Time history of the angular velocity of stroke motion

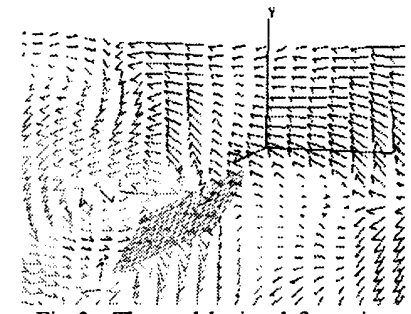

Fig. 3 The model wing deformation and the fluid velocity field around the model wing.
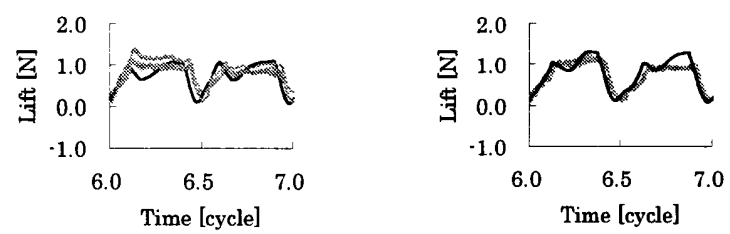

(b) $t_{\mathrm{a}}=T_{\phi} / 8$

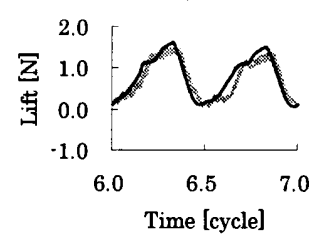

(c) $t_{\mathrm{a}}=T_{\phi} / 6$

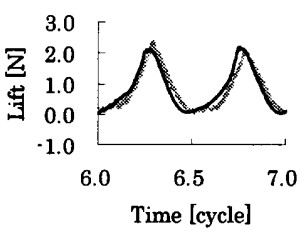

(d) $t_{\mathrm{a}}=T_{\phi} / 4$

Fig. 4 Time histories of lift forces acting on the model wing. The black lines indicate the numerical results, while the grey lines indicate the experimental results.

\section{参考文献}

(1) Yamada, T. and Yoshimura, S., Computer Modeling in Engineering \& Sciences, $24,51-60,2008$

(2) Minami, S. and Yoshimura, S., Journal of Computational Science and Technology, 3, 396-407, 2009.

(3) Ishihara, D. and Yoshimura S., International Joumal for Numerical Methods in Engineering 64, 167-203, 2005.

(4) Washio, T., Hisada, T, Watanabe, H. and Tezduyar, T.E., Computer Methods in Applied Mechanics and Engineering, 194, 4027-4047, 2005.

(5) Matsumoto, J. and Kawahara, M, International Joumal of Comprotational Fhid Dynamics, $15,33-45,2001$

(6) 松本純一，鈴才健 手塚明，計算工学講演会論文集 8,609-612,2003.

(7) Noguchi, H and Hisada, T., Computers \& Structures, 47, 699-710, 1993.

(8) Tezduyar, T.E. et al., Computer Methods in Applied Mechanics and Engineering, 95, 221-242, 1992

(9) Ishihara, D., Yamashita, Y., Horie, T., Yoshida S. and Niho, T., Joumal of Experimental Biology, 212, 3882-3891, 2009. 